Technological Cooperation among Developing Countries (TCDC). On the science, said Dr Oldham, the meeting took "a very positive approach". Whereas it could have become a forum for recriminations, looking only for controls on the negative effects of collaboration, the workshop took pains to find ways of enhancing the benefits.

The workshop recognised that it was developing guidelines in an area which was relatively little researched. "We had to go by anecdotes," said Dr Oldham. SPRU's own 'Project Perseus', which had looked at the effects of international collaboration among OECD countries (principally Europe, America, and Japan), had run into a problem in defining 'success', and had been unable to come to many policy recommendations - except to point out that the more basic the research, the more successful the collaboration.
Beyond that, some work in Thailand had shown that the most highly regarded research had involved longperiod collaborations.

The rest lay with hearsay and experience, said Dr Oldham, though he was inclined to accept the views of one of the most experienced members of the workshop--Dr Nayudamma, sometime head of both the central leather research institute, Madras, and India's CSIR. Nayudamma criticised the international organisations such as FAO, UNIDO, ILO, UNESCO, WHO, UNEP, and ESCAP, who he said had all tried at one time or another to claim leather as their territory, all, said Nayudamma, "fishing for projects". Success came, according to Nayudamma: when there was clear understanding of the purposes of the collaboration on both sides; when the main objective was the active building up of local expertise; when there was trust and friendship at the top; when statuses were equal; when consultation was continuous; and when the research was more basic than applied.

"As a researcher," said Dr Oldham, "I've felt the need for information. The anecdotes might be aberrations. It looks like an interesting topic for further research. But the developing countries have a very considerable concern about the experience of collaboration. All of us must take this very seriously".

Robert Walgate

Nature would welcome hearing from scientists, particularly in the third world, whose experience of scientific collaboration between the first and third worlds might shed light on this issue
A RECENT visit to eastern Asia allowed me to see something of the pollution problems in several countries. During the last twenty or so years, since the world-wide public interest in the environment has developed, Japan has been castigated as the prime example of the danger of pollution from rapid industrial growth. Every text in this field describes horrific air pollution in Tokyo and other cities, as well as the tragic mercury poisoning at Minnemata.

My first impression of Tokyo was one of surprise; the air seemed as clean as that of London. This impression was confirmed when I visited the Environmental Agency, and met Dr Michio Hashimota, Director of the Air Quality Bureau. I saw the records which showed that up to some ten years ago the air in the Japanese cities deserved its reputation, but that since then the improvement had been spectacularly rapid. Levels of smoke and soot are now as low as in most western cities, and those of sulphur dioxide are lower.

This improvement is the result of vigorous government action, with scientists like Dr Hashimoto in the van. Up o to the mid nineteen sixties, he said "Japan had been heaven for polluters". Now this had changed, and "For the last ten years, it has been hell". The earlier period had been that of the 'Japanese miracle' of unprecedented economic growth, when the environment had come a bad second. However, those who said that growth and pollution must always go hand in hand have now been shown to be wrong. It is true that the rate of growth has slowed down somewhat, but the process has not been reversed. The clean air of today exists with substantially greater industrial production than existed with the foul air of ten

years ago.

Although Japan has not solved all its problems, the impressive new Institute for Environmental Studies, with facilities most scientists in other countries would envy, demonstrates their intention to prevent anything like a

\title{
Heaven and Hell
}

\section{Sorry, for copyright reasons some images on this page may not be available online}

\section{KENNETH MELLANBY}

second Minnemata. Regulations are strictly enforced, and controls are costing industry a great deal of money. However, it is realised that this may sometimes be a good investment. Quite apart from the loss of life and the misery caused to the afflicted, it now appears that the sum that has been paid in compensation to the Minnemata victims is astronomically greater than it would have cost to contain the waste mercury discharged by the industry.

Conditions today are somewhat dif- ferent in South Korea and Taiwan. In both these countries industrial growth of the kind previously seen in Japan is taking place, but the programme of both growth and of environmental amelioration is ten years behind. Pollution control is not yet a priority, though the authorities are now becoming aware of the problem, and I expect they will soon follow Japan's good example. But they have not yet started to do so. In Taiwan, on the edge of the booming city of Taipei, just beyond the new and magnificent Grand Hotel, rises the mountain of Yang-min Sang. This was once noted for the purity of its air, one reason why before dawn hundreds of Chinese trek upwards to sites where they perform Tai Ch'i Chuan, Taikwondo, Karate and other exercises and martial arts practised to develop mental and physical fitness. Unfortunately the devotees are not getting the benefit of pure air, for this today is much more polluted than that of central Londonor of Tokyo.

Some European environmentalists are reluctant to believe that the conditions in Tokyo are so improved. They produce photographs of the citizens in the streets wearing masks over their faces, which they say is done because of the dirt in the air. This suggestion amuses the Japanese, who actually are only being socially responsible. They wear masks when they have a cold and do not wish to infect their colleagues. They have taken the transmission of infection more seriously than we have in Britain, where the war time slogan "Coughs and sneezes spread diseases' seems to have been forgotten, judging from the behaviour of many passengers in public transport who make little attempt to keep their germs to themselves. 